\title{
Problems of economic globalization of China as a factor of cultural security
}

\author{
Olga Borisenko ${ }^{1, *}$, Dmitry Sukharev ${ }^{1}$, Marina Fomina ${ }^{1}$ and Nataly Kondakova ${ }^{1}$ \\ ${ }^{1}$ Transbaikal State University, 672039, Aleksandro-Zavodskaya str., 30, Chita, Russia
}

\begin{abstract}
The article is devoted to the analysis of the problems of economic globalization in China and as a factor of cultural security. A philosophical analysis of the social aspect of China's regional development. J. Sigurdson, like many researchers, analyzes economic, political factors, technological innovations, regional development programs of China. Our attention was drawn to the fact that he is one of the few Western researchers who analyze social problems. J. Sigurdson gives an analysis of Chinese society in the context of the development of technological systems. He notes that the creation of clusters, the use of new technologies contribute to the development of the social infrastructure of modern Chinese society. It is worth noting that his analysis is based on the historical information approach. In this case, we are not interested in ascertaining the facts presented by him, but in describing the role of innovation systems in the development of the social sphere of Chinese society. Thus, the relevance of this article is due to the need to analyze Western research on the social factor of regional changes in China. The entry into globalization processes and the perception of the economic opportunities of the modern world in China is refracted through traditional culture and allows not only to preserve its own values, but also to successfully adapt them to the realities of the present day on one hand and spread it outside on the other. China plays an important role in the modern economic development of the world. The main task of the Chinese strategy for the development of clusters was to ensure that the results met not only the economic development of the country, but also the rise of the social, cultural component. The Chinese government is aware of the depth of existing problems in society, and how we see new promising plans for the development of China's economic system. In the artical, we allows us to view modern China not only as a simple element of the world economic system, but rather as one of the leading subjects of economic globalization, actively participating in the world economy and making a significant contribution to the development of the modern world. In our view, it is the integrity of the domestic political and foreign policy course of the country's development that allowed the Chinese economy and culture to become a visible and important element of the world economy.
\end{abstract}

* Corresponding author: olenka_rabota@mail.ru 


\section{Introduction}

The development of the modern world can not be imagined without interconnection with the processes of globalization, all spheres of human life are transformed. It is worth noting that globalization has a great impact on culture, education, and communication. However, the globalization of the economy lies at the basis of the processes of globalization of politics, culture and other spheres. Indeed, it is the expansion of the economic space, the development of transnational corporations that have become the first on the path of interaction and mutual exchange. S.N. Bunchuk says that globalization in the sphere of economy is changing the very economic space, new forms and ways of interaction appear in it. For new forms of economic space, "dynamic development, concentration of economic gaps and contradictions, expansion into the national economy"[4,18]. As an example of the form of the new economic element, it leads free economic zones and transnational corporations. The activities of TNCs show flexibility and dynamism, which make it possible to respond more flexibly to the challenges of the modern world and preserve their capitals and spheres of influence.

The national character of culture has irreplaceable and unique features. If a culture loses its national identity, it loses its vitality. However, we must recognize that in the era of globalization, human culture has demonstrated unprecedented and strong integration. In the "integration" trend, each ethnic culture is concerned about the loss of its own cultural characteristics, especially weak cultural subjects must always protect themselves from a strong cultural subject in order to establish their culture as universal. In this case, we observe the expansion of Western culture to the eastern.

In modern society, being in the process of economic globalization is an extremely important factor for successful development for both individual companies and for the state as a whole, and we can observe how fast the growth rate of the economy is observed in countries that have successfully entered globalization and how far behind those who does not accept the conditions of a globalizing world. Globalization processes cause significant changes in the entire world economic system, economic ties are established between companies regardless of state borders and cultural spaces. All the territories covered by the economic processes of globalization become a single economic space. Do not forget that globalization processes are accompanied by information and technological shifts, commodity and money flow intensifies, the role of individual regions in the integrated economic system is changing. The main role in social and economic development begins to play large transnational corporations, combining the achievements, capital, labor power of different countries and cultures. As S. Bunchuk notes, "large corporations in their economic activities began to be guided by the strategy of absorbing space, thereby overcoming national and local integration boundaries"[4,18]. As already noted in the context of globalization, economic interactions between actors are carried out in a single space, regardless of cultural and state borders. Moreover, the development trend of the modern world lies in the fact that "the quality of the interaction of space and time in a given form of economic space is changing: space is increasing and time is becoming denser"[4,8]. As a result of the expansion of territorial borders, the market for consumption of products produced in individual countries and regions is multiplied. Moreover, the perception of time also changes, because for success in modern economic activity it is necessary to be constantly aware of the events, be able to respond instantly to the challenges of modern society, information technologies that help reduce the time for transferring documents, transferring money, buying goods.

Gradually increasing development of manufacturing firms throughout China, entailed the process of their integration into geographical clusters. As noted by the professor of research policy J. Sigurdson, clustering in high-tech sectors can form a completely different 
model. This is due to the fact that, in addition to the geographical component, it should also include sectoral or functional characteristics. However, in China, the distribution of technological opportunities in geographical space creates an uneven division, which is not a national but a regional one. Given this factor, J. Sigurdson defines three types of regional agglomeration. To them he relates:

- "traditional clusters" that exist in regions where there is a strong industrial base, which naturally provides good conditions;

- the second type corresponds to regions in which high-tech activities are supported by the policy of border research;

- the third category includes regions that have a weak production and technological base $[13,23]$.

\section{Materials and Methods}

The typology of J. Sigurdson clusters is consonant with the position of M.L. Titarenko, who noted the following. In the process of creating clusters, "Chinese party leaders and economists actively took into account and creatively rethought the economic experience, the history of the ups and downs of the economies of many countries, including the experience of Japan and the" Asian tigers "- Taiwan, Singapore and Hong Kong, South Korea, as well as the NEP experience in THE USSR." [6, 167].

Titarenko M.L. concentrates on the fact that in Chinese society, the changes were coordinated with a clearly defined task and traditional ideology. This allows us to define a "distinctive feature", the meaning of which is, writes ML. Titarenko, that a strategy was developed and "long-term stage-by-stage planning in solving specific problems of development" [6, 166-167]. Appeal to the latest Russian studies, for example, to the works of D.A. Izotova [1], O.V. Korneiko and A.V. Pestereva [2] makes it possible to note that the conceptual position of ML is traced in them. Titarenko about the essence of Chinese clusters. It should also be noted that the social nature of clusters is represented in studies, for example, V.S. Morozova [3], which defines the strategy for the formation of sociocultural clusters in the Sino-Russian border area.

Thus, we note that the main task of the Chinese strategy for the development of clusters was to ensure that the results met not only the economic development of the country, but also the rise of the social, cultural component. According to J. Sigurdson in China, the second category of clusters prevails. He explains this by the fact that on the one hand, there is an inherent conflict between regional or localized development and rapid concentration of production and technological activities, on the other. He notes that scientific and technical parks are unevenly distributed in China, which in fact does not allow the distribution of the population by economic activities. At the same time, J. Sigurdson notes that politicians in many countries were fascinated by the idea of creating a Silicon Valley in China. This is because clusters were able not only to support technological development, but also to support GDP growth to create new jobs $[13,6]$.

Undoubtedly, development within the framework of economic globalization with the participation of transnational corporations is proceeding at a faster pace, due to their size and flexibility, TNCs can respond in a timely and effective manner to fluctuations in national economies and overcome economic crises by redistributing their resources. Thus, TNCs become an integral part of today's economic processes, and the economic globalization of countries and regions becomes a condition for the successful development of national and regional economic systems.

One of the states that took globalization and entered it was China. To date, China's economy is developing at a rapid pace, growing GDP, investment and foreign trade. Analyzing the economic development of China, A.V. Lubomudrov stresses that there is no 
unambiguous answer to the question about the factors and conditions for the rapid development of the Chinese economy in the ongoing studies.

He writes that most researchers take the lead in the development of China's economy to the reforms carried out in the country, and not less than a number of authors insist on a breakthrough due to economic liberalization and reduction of state interference in business activities. Presenting the official position of the CCP on this issue, A.V. Lubomudrov notes that "the path to socialism with Chinese characteristics was paved", combining the plan and the market, reforms and stability, economic efficiency and social justice, external and internal factors of growth" [13,11].

I. Gladkikh, analyzing the issues of building a long-term strategy for the development of countries and its implementation, stops its attention on the PRC. On the example of the PRC, he shows a theoretical model for building long-term strategies for the development of national economies.

He notes that this strategy in the PRC is quite successful, especially in the field of modernization of such spheres as industry, agriculture, defense, science and technology. In addition, there is a constant GDP growth in China. I. Gladkikh writes "building a society of" modest prosperity "(xiaokang) - was achieved in 2000. The concept takes into account the traditions of China, involves their use in terms of growth factors and adaptation to changes in internal and external conditions"[8].

\section{Results and Discussion}

We should not ignore the problems connected with the implementation of the Concept, among these shortcomings, one can note the uneven development of the economies of different regions of China, the weak development and implementation of scientific and technological achievements in the economy, as well as low per capita incomes of rural residents. I. Gladkikh believes that such shortcomings are expected, since the country implements "an extensive development path (the model of" catching up "development)" [8].

In general, the improvement of the economic system of China remains incomplete, however, the noted shortcomings are realized by the Chinese government and in the strategy of economic development in 2018 development of the scientific and technical sector, poverty reduction and the construction of the middle class, as well as support for entrepreneurial activity is considered one of the priority directions.

Solving the problems of poverty reduction is a rather complicated task and as noted by Vasyukhin O.V. and Hewei its complexity lies in the depth of the causes that generate poverty. For these reasons, they include "unfavorable geographical and climatic conditions, a complex ecological situation, underdevelopment of economic, social, entrepreneurial, cultural infrastructure, excessive reliance on external assistance" [11]. Nevertheless, the Chinese government is aware of the depth of existing problems in society, and how we see new promising plans for the development of China's economic system. As Li Jinwen notes, "the standard of living of the people as a whole has reached the indicators of so-called small welfare. In the 21 st century, China's strategy of moving to the category of countries with an average level of development will be implemented, which will be a new milestone in the history of the development of the Chinese economy" [22].

For China, knowledge is the basis of economic development. Thus, J. Sigurdson notes that knowledge and communication flows have become key elements of knowledge-based production. This is facilitated by the fact that traditional universities and colleges are increasingly supplemented by scientific centers or research institutes, since an increasing proportion of new knowledge is generated in corporate laboratories [13,39]. Consequently, knowledge becomes more and more differentiated to meet different needs and conditions. 
Researchers of China's economic development Tsvigun I.V., Meng Demin emphasize the importance of China's entry into the system of economic globalization and the activities of transnational corporations in modern economic activity. They note that "Thanks to the policy of reform and opening up, China has already become involved in the process of economic globalization. Since then, as in the 1994's. the world-famous TNCs deployed a strategic investment business network in China, the processing industry of the PRC has become a notable phenomenon in the world economy" [16]. To date, we are faced with products manufactured in China in virtually all industries. Tsvigun I.V., Meng Demin also believe that the successful development of processing industries in China is associated with a change in the structure of the economy, with its order and the movement of international production. However, here there is another problem that Tsvigun I.V., Meng Demin, Vasyukhin O.V., Hewei, Li Jinwei pay attention to it is connected with the dependence of the Chinese economy on foreign capital in the international division of labor. Li Jinwei also focuses his attention on the need to improve the structure of production.

Since transnational corporations play a leading role in the processes of economic globalization, not all the states included in this process concentrate on their territory a full cycle of production and accordingly do not receive all the profits from the "market sale of products with high added value [16]. Because of this, the concentration of only the processing industry in its territories allows it to be located only in the lower position of the international production chain. Here there is a need for expansion of production, redistribution of the sales market and, of course, a full cycle of production with the latest technological achievements. This will allow the Chinese economy to develop more successfully under conditions of economic globalization.

In our opinion, the current state of the social and economic sphere in China and the country's long-term development plans allow solving the identified problems to a greater extent, because already today China itself attracts other countries for processing, acting as an investor and producer.

Economic globalization combined with the preservation of the values of China's traditional culture allows us to build long-term and predictable scenarios for the development of society. As E.O. Olikh's traditional values are not perceived in China as something backward, on the contrary, "the adherence of the society to traditions not only allows it to remain stable, but also makes it possible to predict the course of events" $[16,63]$. The entry into globalization processes and the perception of the economic opportunities of the modern world in China is refracted through traditional culture and allows not only to preserve its own values, but also to successfully adapt them to the realities of the present day on one hand and spread it outside on the other.

\section{Conclusions}

Globalization allowed China to assess the available external and internal resources and effectively use them in its foreign economic activities. Thanks to the opportunities presented, China began to attract foreign investments to the country's development, as well as scientific and technical achievements, modern management technologies. Opportunities appeared both for training their own specialists in large scientific and technological centers of the world, and for attracting specialists from different areas to work in China. In addition, China began to participate in foreign economic activities, invest in multinational companies, expand the distribution network of Chinese goods and popularize Chinese culture.

Tsvigun I.V., Meng Demin in detail analyze the issues related to "going abroad" of China. They note: "One of the main ways to increase China's role in the international division of labor is to create and strengthen its own transnational companies, which allows 
using various factors of production on a global scale in the interests of the development of the country" [21]. This strategy will allow Chinese enterprises to participate more actively in international economic activities, develop their own transnational corporations, participate in investment processes, and create their own trademarks competing with wellknown global brands. China plays an important role in the modern economic development of the world. Lubomudrov, he believes that China not only entered the world economic arena, but also strengthens its positions, defends its own interests. He processes of economic globalization, in addition to the opportunities for developing national economies and increasing profits, also carry certain risks and dangers, for example, world economic crises that affect not only international companies, but also have a negative impact on national economies. However, A.V. Lubomudrov emphasizes that "China has been sufficiently prepared and to the negative consequences of globalization" [13,3]. And China during the global financial and economic crisis showed "a high dynamics of economic growth" $[13,3]$. This fact, of course, allows us to view modern China not only as a simple element of the world economic system, but rather as one of the leading subjects of economic globalization, actively participating in the world economy and making a significant contribution to the development of the modern world. In our view, it is the integrity of the domestic political and foreign policy course of the country's development that allowed the Chinese economy and culture to become a visible and important element of the world economy.

To summarize, I would like to note that China's modern economic development allows it to occupy a leading position in the world, successfully resolving its own internal economic problems and exerting a significant influence both on the states bordering China and on the countries of Western Europe and the United States. In our opinion, the combination of traditional culture and the tendencies of modern development of the world allows China to preserve its identity on the one hand, and on the other, to be an essential element of modern economic globalization processes.

The article is executed within the framework of the state task 35.9234.2017/БЧ.

\section{References}

1. Bob Jessop, Journal of Ritsumeikan Social Sciences and Humanities, 5 (2013)

2. O. A. Borisenko, M. N. Fomina, Social Science and Humanity, 3 (2016)

3. O. A. Borisenko, M. N. Fomina, SCO in the context of a global outlook (Publishing House of the Academy of Natural History, Moscow, 2016)

4. S. N. Bunchuk, Forms of economic space in the context of the globalization of economic relations Step, Candidate of Sciences: 08.00.01. (Moscow, 2006)

5. J. Sigurdson, China becoming a technological superpower - a narrow window of opportunity (https://core.ac.uk/download/pdf/7092081.pdf, 2004)

6. Cong Cao, Richard P. Suttemeier, and Denis Fred Siman, Physics Today, 59, 12 (2006)

7. Daniel C. O'Neill, One Belt, One Road, One Regime Type: The Limits of Chinese Influence in Developing States. ISA International Conference 2017. June 5, 2017 (University of the Pacific School of International Studies, Hong Kong, 2017)

8. I. Gladkikh, Economics and Management: Research and Practice Journal, 3 (2015)

9. D. A. Izotov, Specificity of cluster structures in the Chinese economy. Regionalistics, 2, 3 (2015) 
10. O. V. Korneiko, A. V. Pesterova, Bulletin of the Udmurt University. Series "Economics and Law" (2016)

11. Li Jinwen, Problems of Forecasting, 4 (2001)

12. Liu Xizhong, China Nanjing, 5 (2014)

13. A.V. Lyubomudrov, The role of China in the globalization of the world economy (Moscow, 2011)

14. Michael D. Swaine, China Leadership Monitor, 47 (2015)

15. V. S. Morozova, Russia and China: Problems of Strategic Cooperation: A Compilation of the Eastern Center, 15 (2014)

16. E. O. Olikhova, Bulletin of the Moscow State Linguistic University, 11 (2010)

17. Jon Sigurdson, Regional innovation systems (RIS) in China (https://swopec.hhs.se/eijswp/papers/eijswp0195.pdf, 2004)

18. D. V. Sukharev, M. N. Fomina, O. A. Borisenko, T. V. Bernukevich, N. S. Kondakova, Chinese regionalism as a factor of modernization (The publishing house of the Academy of Natural History, Moscow, 2017)

19. D.V. Sukharev, O. A. Borisenko, M. N. Fomina, Economics and Management of Innovative Technologies, 1 (2016)

20. M. L. Titarenko, Russia and its Asian partners in a globalizing world. Strategic cooperation: problems and prospects («FORUM», Moscow, 2012)

21. Jon Sigurdson, Jiang Jiang, Xinxin Kong, Yongzhong and Yuli Tang, Tehnological Superpower China (Monograph Book) (China, 2005)

22. I. V. Tsvigun, Meng Demin Formation of Chinese transnational corporations on the basis of the state strategy of "going abroad" (BSUEP, Irkutsk, 2010)

23. O. V. Vasyukhin, HeVei, Collected papers of the III International Scientific Conference "Problems and Prospects of Economics and Management" St. Petersburg, December 2014 (Zanevskaya Square, SPb, 2014)

24. New wave of regionalism and strategic choice of China // Economic Information Daily (http://news.sina.com.cn/o/2015-10-16/doc-ifxivsee8281705.shtml, 2016)

25. Xing Lijuan, New regionalism and the system of multilateral economic: conflict and coordination (Chinese Academy of Social Sciences, 2016) 